\title{
Correlation of regional innovation policy and private enterprise independent innovation capability
}

\author{
Ying-jie Zhang \\ College of Economics and Trade of Taizhou University, Taizhou, China \\ Email: hitxinxinzhang@163.com
}

\begin{abstract}
Keywords: regional innovation policy; independent innovation capability; private enterprises
\end{abstract} correlation

\begin{abstract}
Based on some private enterprise, Taizhou, Zhejiang questionnaire from the "regional innovation policy, private enterprise independent innovation capability," explores the contents of two dimensions and characteristics of regional innovation policies, and further analysis of the regional innovation policy and private enterprise autonomy the relationship between innovation capability. Studies suggest that: Regional innovation policy in general have a significant positive impact on private enterprise independent innovation capability; same regional innovation policy there is a significant difference in the degree of support of different enterprises. Therefore, the local government departments to improve relevant policies to improve the capability of independent innovation of private enterprise.
\end{abstract}

\section{Introduction}

With the development of market economy, China's private enterprises have become an important social and economic life of the component. It is in promoting economic growth, job creation and technological innovation to promote economic development and maintain social stability played an important role. As of the end of 2013, China's private enterprises export 916.77 billion U.S. dollars, up 19.1 percent; imports 576.48 billion U.S. dollars, an increase of $27.8 \%$, employing 219 million people is indeed where the private sector 125 million people, 093 million individual business people. ${ }^{11]}$ Private SMEs have become the main force of China's economic growth. The innovation is the life of private enterprise. Academic research and theory on private enterprise shows to promote private enterprise innovation, not only need to increase capital, technology, personnel and other factors of production inputs, but also need the government to give the appropriate policy support.

$\mathrm{n}$ recent years, research on private enterprise independent innovation ability is gradually increasing. However, there is evidence of regional innovation policy studies the impact of private enterprise independent innovation ability is still in the exploratory stage. Zhuping Fang and Dividing incentives for science and technology $\mathrm{R} \& \mathrm{D}$ investment and the impact of patent output of the analysis that the government $\mathrm{R} \& \mathrm{D}$ funding for patent output impact is not significant; [2] Cheng Hua and wanjun1515 questionnaire-based enterprises in Zhejiang found that government policy on the supply of independent innovation capability has promoted, so the government should increase and improve the supply of policy efforts to improve the capability of independent innovation of enterprises; ${ }^{[3]}$ Cheng Hua and Lidong Qin relationship research efforts and technological innovation policy performance noted that China's technology innovation policy efforts to promote the role of technological performance; ${ }^{[4]}$ Zhou Xin-Ping Dong Yun and so on through all kinds of Ningbo Science and Technology Policy enterprise survey results, financial investment, tax breaks and other government science and technology policy for innovation has an important impact on corporate behavior; ${ }^{[5]} \mathrm{Li}$ Jiaming and Joe Trimble confirmed by empirical research, industry tax incentives for high-tech industries develop independent innovation capability has a crucial role。[6]

Overall, the current capability of independent innovation on private enterprise research is mostly limited to specific policies, less involved regional innovation policy system research and innovation policy implications on regional systematic and empirical discussion is scarce. In view of this, the 
article based on the survey results, Taizhou, Zhejiang part of private enterprises, the relationship between the content and depth of regional innovation policy and private enterprise independent innovation capability of regional innovation policies aimed at private enterprise independent innovation capacity of regional policy level study provides abundant practical basis, while strengthening regional innovation policies to promote private enterprise independent innovation capability application made suggestions for improving the relevant government departments.

Study Design. The study was part of Taizhou City, Zhejiang private enterprises as the research object, using questionnaires, survey research to innovation policy, innovation and ability to quantify the questionnaire as a measurement tool to collect data. Questionnaire is divided into two parts: (1) survey of regional innovation policies, including the "supply policy, demand policy, environmental policy basis" in three dimensions, a total of 22 multiple-choice questions; (2) on independent innovation capability of the investigation, including "innovative resource inputs ability, innovation management, innovative R\&D capabilities, innovation and manufacturing capabilities, innovative marketing, innovation output capacity "in five areas. A total of 20 questions, all measurements are made Likert scale (Likert Scales) fifth scale system, which "totally disagree (1 point), disagree (2 points), clear (3 points) , agree (4 points), totally agree (5 points).

Stratified random sampling principle study, a total of 145 questionnaires were 137, recovery 94.48\%; 126 valid questionnaires, the effective rate of $86.90 \%$. Research on measuring the reliability of the questionnaire to measure reliability using split-half method, the reliability coefficient: $\mathrm{R}=2 \mathrm{R} /(1+\mathrm{R})$, Cronbach $\mathrm{Q}=0.94$, the questionnaire has very good reliability; questionnaire in order to determine the validity of the formal former research first select some private Taizhou, Zhejiang SME managers, and managers of innovation policy, makers of the validity of the questionnaire were judged on the questionnaire repeated changes and additions. Finally, to get a more satisfactory final questionnaire. This study is mainly used SPSS 13.0 software for statistical and analysis tools.

\section{Research and analysis}

Taizhou private enterprises independent innovation capability survey

Taizhou state-owned assets in accordance with the exit from the competitive requirements of the field, originally owned more than $90 \%$ of SMEs have completed the reform of the reform, the formation of a large number of non-indigenous ecology of private enterprises, the enterprises in the survey a large number of private enterprises Lord. Since the survey companies to mechanical, chemical, pharmaceutical and other traditional manufacturing enterprises, corporate nature of the item and an industrial asked not deviate statistically sample, therefore, these two will not participate in the analysis as control variables.

Table 1. Taizhou private enterprises independent innovation capability of descriptive statistics

\begin{tabular}{|c|c|c|}
\hline Specific issues & Mean & Variance \\
\hline The corporate emphasis on technological innovation success rate & 3.154 & .054 \\
\hline $\begin{array}{l}\text { The share of corporate technology developers continue to increase the proportion of } \\
\text { full }\end{array}$ & 2.402 & .914 \\
\hline The corporate emphasis on $R$ \& $D$ investment & 2.414 & .947 \\
\hline The company has developed innovative strategies reasonable & 2.402 & .882 \\
\hline $\begin{array}{l}\text { The corporate emphasis on innovative mechanisms to develop a reasonable } \\
\text { safeguards and measures }\end{array}$ & 3.131 & .518 \\
\hline The corporate emphasis on intellectual property and patent protection & 2.412 & .903 \\
\hline $\begin{array}{l}\text { The companies will continue to strengthen the introduction of technology digestion } \\
\text { and absorption capacity }\end{array}$ & 3.145 & .483 \\
\hline $\begin{array}{l}\text { Your business will shorten the new product, new technology research and } \\
\text { development lead time }\end{array}$ & 2.416 & .934 \\
\hline $\begin{array}{l}\text { Your business will continue to improve the level of production equipment, improve } \\
\text { production efficiency }\end{array}$ & 3.826 & .705 \\
\hline Your business will continue to increase the average skill level of workers & 3.125 & .516 \\
\hline $\begin{array}{l}\text { The companies continue to raise the level of the production line of standardized } \\
\text { operations }\end{array}$ & 3.126 & .678 \\
\hline
\end{tabular}




\begin{tabular}{|lcc|}
\hline $\begin{array}{l}\text { Your business will continue to increase investment in innovation and marketing costs } \\
\text { continue }\end{array}$ & 2.385 & .895 \\
$\begin{array}{l}\text { The level of understanding of the enterprise market are very high in the industry } \\
\text { The companies will continue to introduce new products to new products and expand } \\
\text { market share }\end{array}$ & 2.438 & 3.104 \\
\hline The companies continue to raise the level of new product technology & 3.165 & $\mathbf{1 9 1 4}$ \\
\hline
\end{tabular}

Table 1 shows the statistical results, overall, most of the questions of the questionnaire scores between 2.402-3.826, weak in the middle level, indicating Taizhou current research innovation capacity of SMEs is still relatively low, and the enterprise of the low degree of recognition of independent innovation capability.

Correlation analysis of regional innovation policy and private enterprise independent innovation capability.

Enhance the capability of independent innovation of private enterprise is a complex system engineering, not only need to increase capital, technology, personnel and other factors of production inputs, but requires the joint efforts of the whole society, the government is promoting the innovation system, establishing a system to protect and guide the establishment of innovative resources private enterprise into a dominant force in the innovation system. Therefore, to enhance the capability of independent innovation of private enterprise, we must emphasize and play the macro-management and control functions of government, therefore, how to effectively play the macro-management and regulatory functions of government, the use of regional policies to create a favorable environment for innovation, build efficient regional innovation policy to promote private enterprise system and ultimately enhance the capability of independent innovation, the government has become a topic of great concern to the academic and theoretical.

Use of regional innovation policy in supply policy and innovation capacity of SMEs to do correlation analysis of each dimension

Table 2. Correlation analysis of regional supply policy and private enterprise independent innovation capability

\begin{tabular}{|l|l|l|l|l|l|l|}
\hline \multicolumn{2}{|c|}{} & $\begin{array}{l}\text { Innovation management } \\
\text { capabilities }\end{array}$ & $\begin{array}{l}\text { Innovative marketing } \\
\text { capabilities }\end{array}$ & $\begin{array}{l}\text { Innovation and } \\
\text { R } \begin{array}{c}\text { Innovation } \\
\text { capabilities }\end{array}\end{array}$ & $\begin{array}{l}\text { and } \\
\text { creativity }\end{array}$ \\
\hline \multirow{3}{*}{ Supply policy } & $\begin{array}{l}\text { Pearson } \\
\text { Corre1ation }\end{array}$ & $.394(* *)$ & $.275(* *)$ & $.381(* *)$ & .140 \\
\cline { 2 - 6 } & $\begin{array}{l}\text { Sig. } \\
(2-t a i l e d)\end{array}$ & .000 & .002 & .000 & .118 \\
\hline
\end{tabular}

Note: $\mathrm{N}=126 ; \quad * *$ Indicates significant at the 0.01 level; $\quad *$ Indicates significant at the 0.05 level

The results can be seen from Table 2, the regional supply policy and private enterprise independent innovation capability in innovation management, innovation and marketing capabilities, innovative $R \& D$ capabilities significantly correlated at the 0.01 level, the corresponding correlation coefficient of the $0.394,0.275,0.381$, there is a significant positive correlation between regional supply proof of private enterprise policy and innovation management, innovation and marketing capability and innovative R\&D capabilities; while private enterprises with independent innovation and innovative manufacturing capabilities no significant correlation $(\mathrm{P}>0.05)$. The reason for this condition may be related enterprises in technological innovation process, companies will update the advanced production facilities and equipment, and improving workers' professional skills, these factors of production is relatively stable constant. The current policy is not easy to affect change in the regional supply of these indicators, therefore, in order to improve the production level of innovation, the future government should improve relevant policies and measures in this regard.

\section{Correlation Analysis of environmental infrastructure policy and innovation capacity of SMEs}

Use local government innovation policy in environmental infrastructure policy and put it private independent innovation capability dimensions do correlation analysis. 
Table 3. Correlation analysis of regional environmental policies and basis of private enterprise independent innovation capability

\begin{tabular}{|c|c|c|c|c|c|}
\hline & & $\begin{array}{c}\text { Innovation management } \\
\text { capabilities }\end{array}$ & $\begin{array}{c}\text { Innovative marketing } \\
\text { capabilities }\end{array}$ & $\begin{array}{c}\text { Innovation and } \\
\text { R\&D } \\
\text { capabilities } \\
\end{array}$ & $\begin{array}{c}\text { Innovation and } \\
\text { creativity }\end{array}$ \\
\hline \multirow[t]{2}{*}{$\begin{array}{l}\text { Regional } \\
\text { policy }\end{array}$} & $\begin{array}{l}\text { Pearson } \\
\text { Corre1ation }\end{array}$ & $.218(*)$ & $.652(* *)$ & $.252(* *)$ & .091 \\
\hline & $\begin{array}{l}\text { Sig. } \\
(2 \text {-tailed) }\end{array}$ & .014 & .000 & .004 & .311 \\
\hline
\end{tabular}

Note: $\mathrm{N}=126 ; \quad *$ * Indicates significant at the 0.01 level; $\quad$ * Indicates significant at the 0.05 level

As can be seen in Table 3 above, the regional environmental policy and private enterprise independent innovation capability in innovation management, innovation and marketing capabilities, innovative R\&D capabilities significantly correlated at the 0.01 level, the corresponding correlation coefficients were 0.218,0.652,0.252 prove regional environmental policy and capability of independent innovation capability in innovation management, presentation skills and innovative marketing between innovative $R \& D$ capability significantly positive correlation, indicating that environmental policy management capabilities for enterprise innovation, marketing innovation and enhance innovation capability has a strong $R \& D$ capabilities role; while among independent innovation capability of innovation and creativity no significant correlation $(\mathrm{P}>0.05)$, this is because the basis of the regional environmental policy can not directly affect technological innovation to enhance the ability to create, this situation arising from the government to strengthen environmental infrastructure invest, make up or replace the infrastructure or the environment of the past should be borne by businesses to invest.

Analysis of regional needs related to SME innovation policies and the ability of private Table 4. Correlation analysis of regional needs policy and private enterprise independent innovation capability

\begin{tabular}{|l|l|c|c|c|c|}
\hline \multicolumn{2}{|c|}{} & $\begin{array}{l}\text { Innovation management } \\
\text { capabilities }\end{array}$ & $\begin{array}{l}\text { Innovative marketing } \\
\text { capabilities }\end{array}$ & $\begin{array}{l}\text { Innovation } \\
\text { R\&D capabilities }\end{array}$ & $\begin{array}{l}\text { Innovation } \\
\text { creativity }\end{array}$ \\
\hline $\begin{array}{l}\text { Regional needs } \\
\text { policy }\end{array}$ & $\begin{array}{l}\text { Pearson } \\
\text { Corre1ation }\end{array}$ & $.208(*)$ & $.008(* *)$ & $.062(* *)$ & .161 \\
\cline { 2 - 6 } & $\begin{array}{l}\text { Sig. } \\
(2-\text { tailed) }\end{array}$ & .014 & .917 & .498 & .072 \\
\hline
\end{tabular}

Note: $\mathrm{N}=126 ; \quad * *$ Indicates significant at the 0.01 level; $\quad *$ Indicates significant at the 0.05 level

From Table 4, the results can be found, regional policy and the needs of SME innovation capacity in the private innovation management capabilities significantly correlated at the 0.05 level, the corresponding correlation coefficient of 0.208, indicating that the region needs the private SME innovation policy and innovation capability there was a significant positive phase between management capabilities, is showing between private independent innovation capability of SMEs in innovative marketing capabilities, innovative R\&D capabilities, innovation and creativity was no significant correlation. This shows that the region needs to improve private SME policy can promote technological innovation capability; innovative marketing capabilities for the enterprise, the role of innovation and R\&D capabilities followed; also can be seen from the statistical analysis, Taizhou private enterprises innovative marketing capacity building support not high, and the region needs to change the policy did not affect the ability to create private SME innovation, which is subject to the relevant government departments in the future to continue to strengthen and improve policies and measures related aspects.

\section{Conclusions and recommendations}

Conclusions.According to the correlation analysis results can be seen , the government policy to promote regional independent innovation ability of private enterprises and private enterprises independent innovation capability in innovation management capabilities, showing between innovative R \& D capabilities and innovative marketing capabilities of the three dimensions of a significant positive correlation sex. At the same time, you can also see the introduction of local government to promote private enterprise Taizhou innovation system of regional policy and private 
enterprise independent innovation capability in innovation creativity no significant association , instructions for Taizhou traditional manufacturing -intensive, are now Taizhou a series of regional policy measures taken by the Government to private enterprise innovation no significant role in promoting creativity, which needs to be improved in this respect in the future Taizhou city government related policy measures.

Research shows , Taizhou not yet formed a " market-oriented" to promote private enterprise independent innovation capability of regional policy system. Taizhou has been promoting independent innovation capability of regional policy in the policy performance of excessive demand, the government and sometimes even directly involved in the organization or conduct some business innovation through policies and measures related to government expenditure, R \& D funding , etc., interfere with their cooperation enterprise's internal affairs .

Proposal. According to the research findings, Taiwan City private enterprise innovation policy development and perfection of the application the following recommendations:

Industrial building with ideas to guide private enterprises to enhance the capability of independent innovation of regional innovation policy support system . Technological innovation is a decisive factor in the sustainable development of enterprises, only continue to improve technological innovation ability of enterprises to achieve technological leaps and bounds, in order to provide a strong technical support for enterprise development. To this end, the future of local government should be thinking Taizhou metropolitan innovation system development, to intensify supply policy, basic environmental policy guidance in support of innovative behavior, to encourage independent innovation and implementation of a series of institutional and policy innovation , such as the patent system, reward system invention, technological innovation tax incentives, subsidies to local government finance, education and training programs in basic research investment for the construction of multi-level scientific and technological input system, run the foundation. For this reason, only the establishment has only comply systematic, forward-looking features of regional innovation policy toward Taiwan City can truly independent innovation ability of private enterprises play a sustainable role in promoting improved.

Regional policy to improve the supply of private small and medium enterprises to promote innovation. The study found that the supply of policies to promote private SMEs to improve management capability of independent innovation , R \& D capabilities, innovation and marketing capabilities. Therefore, Taizhou relevant departments should continue to strengthen and improve Taizhou supply policy, with emphasis on fiscal policies, human resources strategy, public support and other aspects of the policy . In terms of fiscal policies, the government should first increase financial investments in technology, integration, and integration of different departments, different channels of financial resources, limited funds led to greater investment of the whole society, and improve government procurement policies to support innovation , enterprise and gradually form dominated the whole of society, science and technology into new multi-channel system . To this end, Taizhou City in investments in technology while seize key areas, increase market prospects , a huge economic input into SME Technology Innovation Fund to fully enhance the efficiency of the management and investment of government funds ; Followed by a multi-level capital market , strengthen the guidance and support of venture capital . Experience of developed countries shows that the high-tech industry in the process of mutual interaction and multi-level capital market innovation of enterprises, the financial capital of decentralized innovation of high-risk mechanism for promoting technological innovation engine. To this end, Taizhou should establish and improve policy through the financial system , technological innovation is the creation of a sound private financing channels for SMEs. Meanwhile, to further improve the multi-level system of credit guarantees and risk capital market regulations, guidance and support effective docking of capital and technology. In terms of talent strategy, innovation and entrepreneurial talent to optimize the environment, while continuing to strengthen the construction of high-end talent, but also accelerate the development of talent training mechanism innovation, mainly to encourage universities, research institutes as the basis to establish a learning enterprise, to promote innovation organization with universities, research institutes, including corporate training innovative talents enterprise 
technology research and development, technology promotion and other aspects of intellectual property assessment . On the government's public service support, Taizhou local government must address public R \& D organizations and public service platform is not perfect situation, strengthen the government's public service functions, nurture and build Taizhou technology research and development, inspection, information technology consulting services and other public platform , meanwhile, should guide the world's leading science and technology agency to establish cooperation in the demonstration area , a joint venture or a wholly-owned service organization , established specialization, standardization and internationalization of technology innovation service platform, where all departments should actively promote the private SME market, listed SMEs will promote innovation and enterprise development work into local plans and programs .

Improve regional environmental policies to promote private enterprise-based innovation . The study found that Taizhou regional environmental policies on private role in promoting SME innovation weakest, but Taizhou regional environmental policies on private SMEs innovation management capabilities, innovative R\&D capabilities and innovative marketing capabilities have a significant role in promoting. Therefore, Taizhou need to further improve environmental infrastructure policies to promote private enterprise independent innovation capability . First, continue to strengthen the industrial base and environmental construction, while increasing stimulate innovation, improve tax incentives, and other innovative reward systems, support and guide the innovation resources to gather private SMEs in Taizhou, therefore , Taizhou relevant government departments should increase in future regional innovation policy propaganda, guide enterprises to grasp and make good use of these regional policies . Second, establish a sound legal system , improve the patent system and the various types of technological innovation activities into the legal system , through the effective functioning of government administration and regulatory bodies, regulate the behavior of private SMEs technological innovation, science and technology innovators to protect the private interests of SMEs . In building intellectual property, intellectual property protection should focus on the construction of the law, so that gradually with international practice.

Increasing regional demand for policy efforts to control private enterprise technological innovation. Regional needs into policy instruments and policy tools to create demand market intervention policy tools include direct support for the establishment of local-level enterprise technical centers in various industries. From the circumstances of this research can also be seen through these studies we found that the region needs to improve private SME innovation policy management capability plays a significant role in promoting . At the same time , this research situation has shown that investment in Taizhou city government needs cooperation and innovation policy is to delegate a lot of big companies, government departments under the guidance and, therefore, the emergence of a large number of Taizhou innovations each year , boosting the many local private small and medium technology innovation, driven by the government sector-led demand to become a big market policy by purchasing some new products, but also further stimulate technological innovation of private SMEs. Especially in the early stages of the product cycle, from procurement needs of government departments stimulating role becomes more important. In order to prevent duplication of blindness in the area of innovation projects, the government must do a bridge enterprises and research institutions, universities, and promote innovative cooperation between enterprises and research institutes to promote policies before Taizhou demand a higher stage development.

\section{Summary}

Improve the ability of private SME innovation needs the support and cooperation of local departments. Therefore, we must establish a mechanism for horizontal coordination between the various sectoral policies, such as the establishment of a coordination mechanism for the financial sector and improve the allocation of resources and technology department of science and technology, establish a coordinated financial sector, science and technology, development and reform, and other related departments to participate in government procurement product innovation 
mechanisms. Meanwhile, building science division, working in collaboration with the mechanism; Finally, the establishment of the government as the main enterprise and innovation intermediaries involved in deliberative bodies, organization and coordination of various policy measures to promote concrete implementation.

\section{Acknowledgement}

Project by the Science and Technology Bureau of Taizhou Soft Science Research Fund (Project number: 131RKX03).

\section{References}

[1] Wang Qinmin(2014). Chinese private economy will undergo change. The Chinese people's Political Consultative Conference Chinese network, http://cppcc.china.com.cn/2014-03/02/content_31642323_2.htm.

[2] Zhu Pingfang. Xu Weimin(2003). An empirical study on the effect of incentive policy of the government of the large and medium-sized industrial enterprises R\&D investment and patent output -- in Shanghai City. Economic research, 6,56-71.

[3] Cheng Hua. Wang Wanjun(2013). Research on the policy and performance of enterprise innovation of Wang Wanjun. China technology forum, 2,10-14.

[4] Li Dongqin. Yang Yongfeng. Money Marat Safin. Chen Liqing(2013). Research on technology innovation policy impact on enterprise innovation performance. Journal of Zhejiang Sci-Tech University, 9,770-774.

[5] Zhou Yun. Dong Xinping. Zheng Yu(2010).An empirical study of Ningbo City Hall technology policy and independent innovation of enterprises, Prices monthly, 1,63-66.

[6] Li Jiaming .Qiao Tianbao(2010). An empirical analysis on preferential tax policy for high tech industry. Technical and economic,2,45-49. 